\title{
Lifetime Bridge Maintenance Strategies Based on System Reliability
}

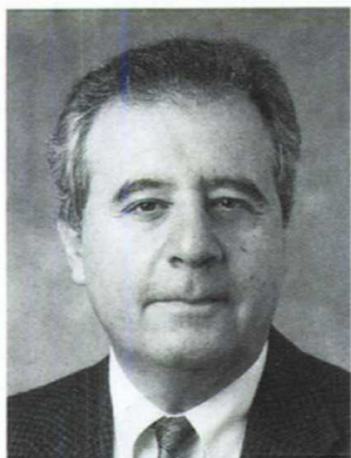

\section{Dan M. Frangopol}

Prof.

Univ. of Colorado

Boulder, CO, USA

Dan M. Frangopol received his civil engineering degrees from the Institute of Civil Engineering, Bucharest, Romania, in 1969 and the University of Liège, Belgium, in 1976. After working in industry in Belgium, he joined the University of Colorado in 1983. His research activities include reliability analysis and design of buildings and bridges, bridge management systems, and structural optimization.

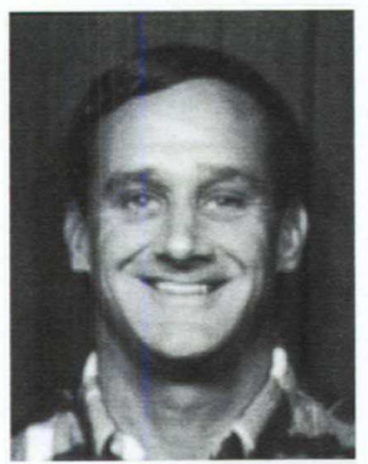

\section{Allen C. Estes \\ Researcher \\ Univ. of Colorado \\ Boulder, CO, USA}

Allen C. Estes is a Lieutenant Colonel in the U.S. Army Corps of Engineers. He obtained his M.S. from Stanford University in 1987. In 1997 he received his Ph.D. from the University of Colorado at Boulder for research about system reliability for the lifetime optimization of inspection and repair of highway bridges.

Peer-reviewed by international experts and accepted by the IABSE Publications Committee

\begin{abstract}
Summary
This study proposes a methodology for a system reliability-based condition evaluation of existing highway bridges. The approach is illustrated for an existing steel bridge located in Colorado, USA. An optimum lifetime repair strategy based on minimum expected cost is developed. The initial optimum repair strategy is updated using both biennial visual inspections and specific non-destructive evaluation testing.
\end{abstract}

\section{Introduction}

Over the past several decades, the concepts and methods of structural reliability have developed rapidly and become widely accepted among researchers and increasingly acknowledged among practicing engineers. The United States has a national inventory of almost 600000 highway bridges, many of which have deteriorated substantially and will require large expenditures to repair. A system reliability approach to optimizing the inspection and repair of these bridges will provide a more efficient use of financial resources by ensuring an acceptable level of safety at a minimum expected cost. For many bridges which were designed and built before reliability methods were applied to structural design, there is an urgent need to quantify their safety from a system reliability perspective [1].

This study proposes a methodology for condition evaluation of existing highway bridges based on system reliability. The approach is illustrated using an existing bridge. An optimum lifetime repair strategy is developed for the bridge by minimizing the expected lifetime repair cost and maintaining a prescribed level of system safety throughout the remaining life of the bridge. This repair strategy is only as valid as the assumptions that were made when the bridge was placed in service. The repair strategy must be updated and revised throughout the life of the bridge based on the results of periodic inspections. The methodology for revising the repair strategy is developed based on both the mandatory biennial visual inspections and some specific non-destructive evaluation testing.

\section{System Reliability for Bridge Repair Optimization}

A time-dependent system reliability approach is applied to optimize the repair strategy for an existing highway bridge, Colorado State Highway Bridge E-17-AH (Fig. 1). The bridge is a three-span, four-lane steel girder structure on State Highway 33 in Denver, Colorado. The length is $42.1 \mathrm{~m}$; the roadway width is $12.18 \mathrm{~m}$; and the Average Daily Traffic is 8500 vehicles. The deck is reinforced concrete and the steel girders are standard rolled shapes with simple-span supports. The interior span supports are reinforced concrete pier columns with a pier cap, four supporting square tapered columns, and individual column footings. The concrete abutments are supported by concrete piles cased in steel. The cross section of the superstructure is shown in Fig. 2a, where the girders are classified as exterior (E), interior-exterior (I-E), and interior (I).

Using 24 random variables, the intact bridge was analyzed with respect to 16 different failure modes including moment failure of the slab, moment and shear failure of the girders, and multiple failure modes of the pier cap, columns and footings. Limit state equations were developed and the reliability of each component was computed separately. The bridge system was modeled as a series-parallel model. Both the component reliabilities and the system reliability of the bridge were computed. A simplified system model for the bridge where it is assumed that the superstructure will not fail until three adjacent girders have failed is shown in Fig. 2b. The simplifying assumptions, a more refined model 


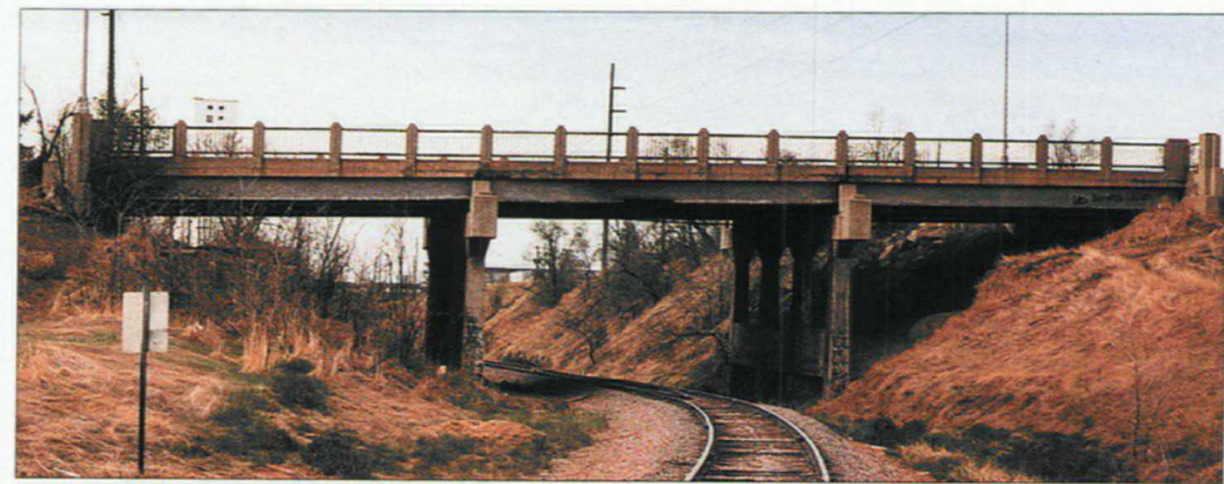

Fig. 1: Colorado State Highway Bridge E-17-AH

and a complete description of these calculations are given in [2].

The reliability of the bridge system is decreasing over time as the live load increases and the structure deteriorates. The time-dependent live-load shear and moment effects are functions of the length of the span, the average daily truck traffic, and the shear and moment caused by an AASHTO HS-20 truck as proposed in [3]. It is assumed that the slab and pier cap deteriorate due to the penetration of chlorides through the concrete as suggested by the methodology developed in [4]. Corrosion begins once the chlorides reach a critical threshold concentration at the level of the reinforcing steel. The time required for corrosion to begin is the corrosion initiation time $T_{I}$. The rate of corrosion $r_{\text {corr }}$ determines the amount of section loss in the reinforcing steel over time. The girders are corroding using the model described in [5]. The corresponding section loss reduces the web area and plastic section modulus over time. This reduces the girder shear and moment capacities, respectively. The deterioration process introduces new random variables into the limit state equations which include diffusion rates, chloride surface concentration, and corrosion parameters.

A minimum allowable (i.e., target) lifetime system reliability index $\beta_{\text {T,system life }}$ $=2.0$ is established. The bridge is in- spected every two years and anytime below the prescribed minimum, some type of repair or replacement must be made. After considering the initial cost of the bridge, cost documents [6] and conversations with experts, the following repair options and their associated costs (in 1996) were established:

\section{0 . Do nothing $\rightarrow$ USD 0}

\section{Replace deck $\rightarrow$ USD 225600}

2. Replace exterior two girders ( $\mathrm{E}$ and I-E in Fig. 2a) $\rightarrow$ USD 229200

3. Replace exterior two girders and entire deck $\rightarrow$ USD 341800

\section{Replace entire superstructure $\rightarrow$} USD 487100

\section{Replace entire bridge $\rightarrow$ USD 659900.}

For option 1 (replace deck), Fig. 3 shows the time-dependent reliabilities of the bridge system and of all bridge components (i.e., slab, girders, pier, and footing) shown in Fig. 2b. The deck is replaced when $\beta_{\text {system }}<2.0$. Consequently, the deck is replaced twice at years 50 and 94 of the bridge life. At year 106, a deck replacement is not sufficient to improve $\beta_{\text {system }}$ to a value larger than 2.0. Due to the parallel nature of the system, the reliability of some components is allowed to fall below $\beta_{\text {Tsystem life }}=2.0$. Due to varying deterioration rates, the critical comthe system reliability of the bridge falls ponent early in the life of the structure is not necessarily the most important later on.

Assuming the bridge was placed in service in 1996, and accounting for all combinations of options and using an assumed discount rate of $2 \%$, the possible repair strategies and their associated 1996 costs are shown in Fig. 4. The analysis continued until replacement of the bridge (i.e., option 5) becomes the only available solution. From Fig. 4, the optimum strategy can be determined for the expected life of the bridge. For example, for a life of 50 years, no action should be taken: for 50-94 years, replace the deck at year 50 (USD 83813); 94-106 years, replace the deck at year 50 and year 94 (USD 118881); 106-108 years, replace the slab at year 50 then replace the exterior two girders and slab at year 94 (USD 136945); and after 108 years, replace the slab at year 50 then replace the bridge at year 94 (USD 186393).

The bridge was analyzed for several different series-parallel system models where the failure of three adjacent girders, or failure of two adjacent girders or failure of a single girder would cause failure of the superstructure. Other parameters such as random variable correlation, deterioration rates, and discount rates were varied and often produced very different results. A repair strategy based on uncertain information must be updated throughout a structure's life based on inspection results. Without a series of specialized tests, the reliability of the bridge when placed in service is based on the same information available to the designer. During the design phase of a structure, the random variables are based on data from other projects, manufacturers' specifications, and available literature. For an existing structure, the availability of material tests and field measurements can reduce the uncertainties in many random variables. a)

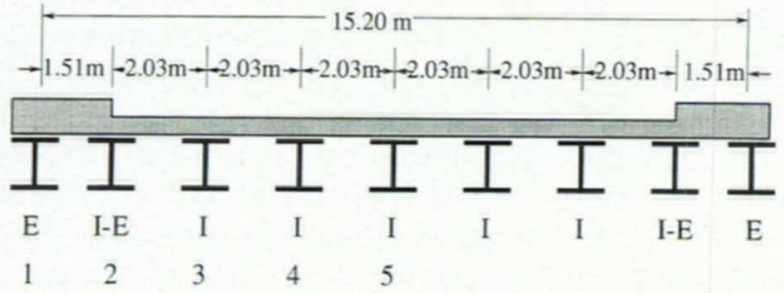

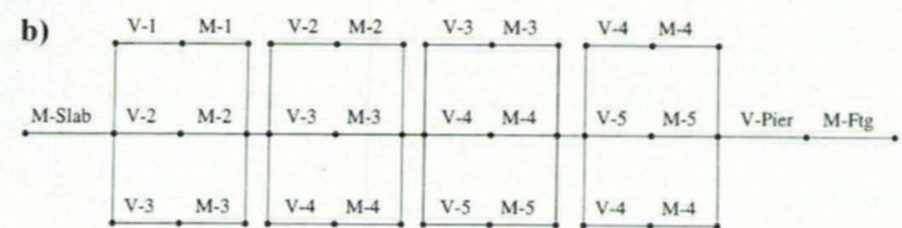

Fig. 2: Bridge E-17-AH: (a) designation of girders; (b) simplified series-parallel model

a) E: exterior girder; I-E: Interior-exterior girder,

$\mathrm{I}$ : interior girder b) V-1: failure due to shear in Girder 1; M-3: failure due to moment in Girder 3 


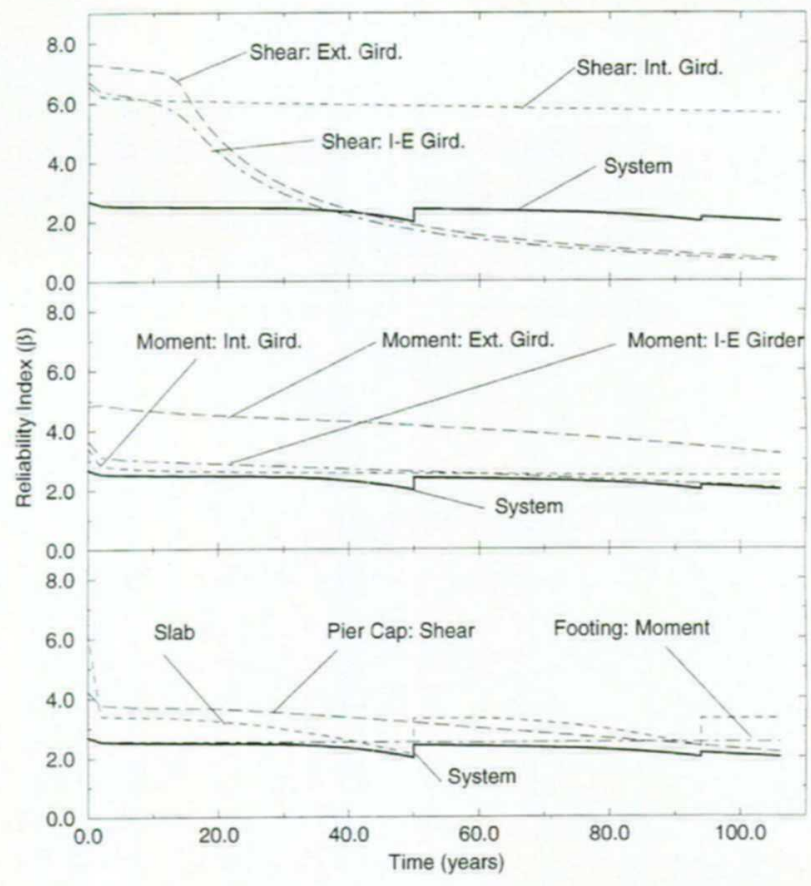

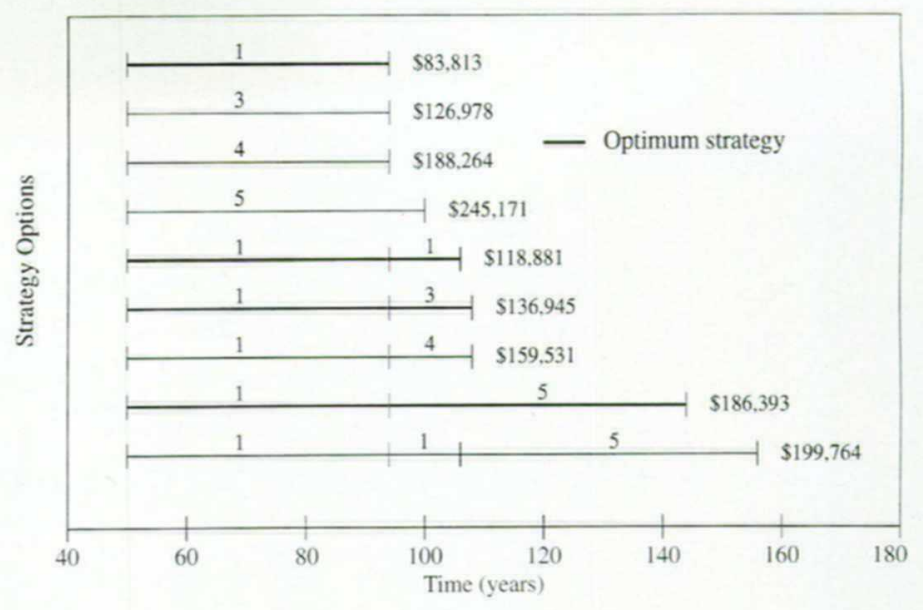

Fig. 3 (above): Results of repair option 1: replace deck on Bridge E-17-AH using series-parallel system model requiring the failure of three adjacent girders

Fig. 4 (left): Strategy options and associated costs
The reliability of a structure can be improved by increasing the capacity of the members, reducing the demand on the structure, or reducing the uncertainty in the random variables. In general, many uncertainties are site specific and if a structure already exists, these uncertainties are lower than those at the design stage [7]. By conducting tests to determine the actual strength of the steel, the unit weight of the concrete, the live-load traffic pattern, the girder distribution factors, or the thickness of the asphalt, the results may allow the subjective uncertainties to be reduced, or even eliminated, and should at least improve the knowledge of the mean value and degree of dispersion of the random variables. A sensitivity analysis would help indicate which tests would produce the greatest benefit. This study, however, is limited to updating the effects of the time-dependent deterioration and updating the chosen deterioration models.

In the United States, all bridges in the National Bridge Inventory must be inspected every two years. The results are reported to the Federal Highway Administration and are maintained in a national database. The minimum reporting requirement is to provide a condition state which ranges from 9 (excellent condition) to 0 (failed condition) for the bridge deck, superstructure, and substructure. As bridge management has improved over the past two decades, many states have adopted bridge management systems and more detailed inspections which pro- vide much more information about an individual bridge. The bridge management system described in [8] has been adopted by many states and assigns condition ratings to many elements of a bridge. These bridge elements incorporate components such as railings, joints and decks; types of materials such as concrete, steel, or timber; and other relevant information such as protected or unprotected decks, open or closed girders, and painted or unpainted stringers.

In the system in [8], each bridge element is visually inspected by a trained inspector and classified into one of five condition states, although some elements have fewer condition states. The five condition ratings for Element 107: Painted Open Steel Girders are shown in Table 1. Updating the reliability of a bridge based on visual inspections is only possible if the conditions states are specific and quantifiable. The condition states in Table 1 rely on rust codes R1 through R4 to quantify the section loss.

The location of the damage also must be known. A segment-based inspection first proposed in [9] is used here. In this manner, the location of all damage on the structure is identified. On the simple-span Bridge E-17-AH, for example, the corrosion near the supports affects the area of the web which reduces the shear capacity of the girder. On the other hand, the corrosion in and/or near the center of the girder reduces the plastic section modulus which is critical to the mo- ment capacity. Furthermore, identifying whether the damage is on an exterior, interior-exterior, or interior girder also affects the system reliability.

CS Description Rust code

1 No evidence of active corrosion. Paint system is sound and protecting the girder.

2 Slight peeling of the paint, light pitting, or surface rust, etc. R1 No section loss.

3 Peeling paint, pitting, sur- R1 face rust, etc. No section loss.

4 Flaking, minor section loss R2 ( $<10 \%$ of original thickness).

4 Flaking, swelling, moderate R3 section loss ( $>10$ but $\leq 30 \%$ of original thickness). Structural analysis unwarranted.

5 Flaking, swelling, moderate section loss ( $>10$ but $\leq 30 \%$ of original thickness). Structural analysis warranted due to location of corrosion on member.

5 Heavy section loss (>30\% R4 of original thickness), may have holes through the base metal.

Table 1: Suggested Condition State (CS) ratings for element 107: painted open steel girders [8] 


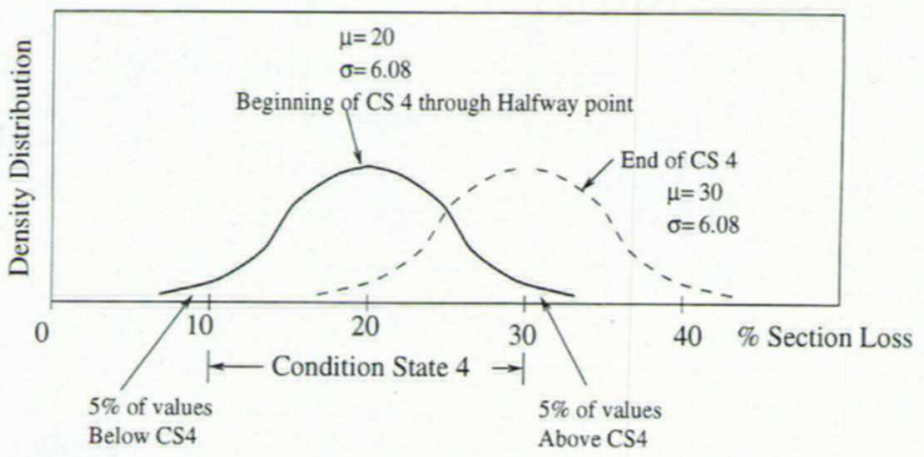

Fig. 5: Density distribution of deterioration for Element 107 in Condition State 4 when inspectors are correct $90 \%$ of the time

$1^{\text {st }}$ half of Condition State: $\mu=20 ; 2^{\text {nd }}$ half: incremental shift from $\mu=20$ to $\mu=30$

The parameters of random variables cannot be obtained directly from a visual inspection. Some assumptions must be made regarding the accuracy of the results and quality of the information provided by the inspectors. This study assumes that condition state deterioration over time is linear and that the deterioration intensity is normally distributed. It is further assumed that when a bridge element is at the halfway point of a specific condition state, the mean value $\mu$ of the deterioration intensity is at the halfway point of the condition state definition (Fig. 5).

The standard deviation $\sigma$ the deterioration intensity is determined by the assumed quality of the inspection program. If the inspector is believed to be correct $90 \%$ of the time when the member is at the halfway point of the condition state, then $90 \%$ of the values in the normal distribution will be within the values prescribed by the condition state. The condition state is assumed to begin at the halfway point and shifts progressively to the right as shown in Fig. 5. If the element remains in the condition state longer than expected, the distribution will remain at the far right position until an inspection reveals a switch to the next condition state. The exception will be for the first and final condition states where a lognormal distribution is used.

This study considered three different qualities of inspection programs, A, $\mathrm{B}$, and $\mathrm{C}$, where the inspectors were provided the correct rating 95, 85, and $75 \%$ of the time, respectively. The quality of the inspection program was determined based on seven criteria [2] which included inspector training, a quality assurance program, and inspector experience. The density distributions associated with condition states 1 through 5 for Inspection Category
A and Element 107 as listed in Table 1 are shown in Fig. 6. Condition states 1, 2 , and 3 were modified to reflect losses in the ranges shown in Fig. 6. Once the parameters of the random variables which describe the section loss for the corroding steel girders are defined, the area of the web and the plastic section modulus at the time of inspection can be computed. With the revised shear and moment capacities of the girders, the updated reliability of the bridge girders is computed. Assuming linear condition state deterioration over time, the future performance of the structure is predicted.

Unfortunately, an update of the deck or superstructure condition was not possible based on a visual inspection. The inspection according to [8] was only able to report the number of cracks, degree of efflorescence, and percentage of surface spalls. While this information is valuable for assessing the general surface condition of the deck or the pier cap, the information was not sufficient to infer the randomness of the section loss in the corroding steel reinforcement embedded in the concrete. A series of non-destructive evaluation inspections are needed to update the reliability of the deck.

\section{Non-destructive Evaluation Methods}

While the biennial visual inspections evaluate the entire bridge, a program of non-destructive evaluation tests focuses on particular defects in specific areas. The tests must be selected to provide the relevant information needed to update reliability. In this study, the thickness of the girder flanges is measured using callipers or a micrometer to obtain actual section loss. For the deck, half-cell potential tests provide the degree of active corrosion and allow the corrosion initiation time $T_{I}$ to be updated. The rate of corrosion $r_{\text {corr }}$ is then assessed using three-electrode linear polarization test results. Because these tests were never actually conducted on Bridge E-17$\mathrm{AH}$, the inspection results from other similar structures were applied to this bridge to illustrate the updating process.

\section{Girder Thickness}

Thickness readings were taken at numerous locations on the girders after 15,30 and 55 years of service. The mean and standard deviation of the corrosion depth $d_{\text {corr }}$ (in $\mathrm{mm}$ ) were established for each type of girder (interior, interior-exterior, and exterior) for each inspection. The same format as that of the original deterioration model $d_{\text {corr }}=\mathrm{A}_{0} t \mathrm{~A}_{1}$ was used where time $t$ is in years. The corrosion parameters $A_{0}$ and $A_{I}$ were computed by a curve fit through the data points, producing the results described in [2].

A comparison of the revised corrosion model [2] with the original corrosion model [5] revealed that the actual rates of corrosion were slightly higher than predicted for the exterior girders, slightly lower than predicted for the interior-exterior girders, and almost the same for the interior girders. The inspection results produced a smaller standard deviation of thickness loss for all types of girders. This reduced uncertainty in thickness loss improves the reliability of the girders.

\section{Section Loss in Deck Reinforcement}

The half-cell potential test is conducted to obtain the percentage of the deck experiencing active corrosion. The half-cell potential survey measures the electrical potential difference between a standard portable coppercopper sulfate half-cell placed on the surface of the concrete and the embedded reinforcing steel. A potential reading more positive than -0.20 volts indicates a $90 \%$ chance of no active corrosion at the point the reading is taken. A reading more negative than -0.35 volts indicates a $90 \%$ chance that active corrosion in underway. Readings between these values are considered uncertain. By plotting a cumulative distribution of the half-cell readings throughout the deck and making a linear approximation in the uncertain range as shown in [10], the percent of the deck which is damaged can be as- 

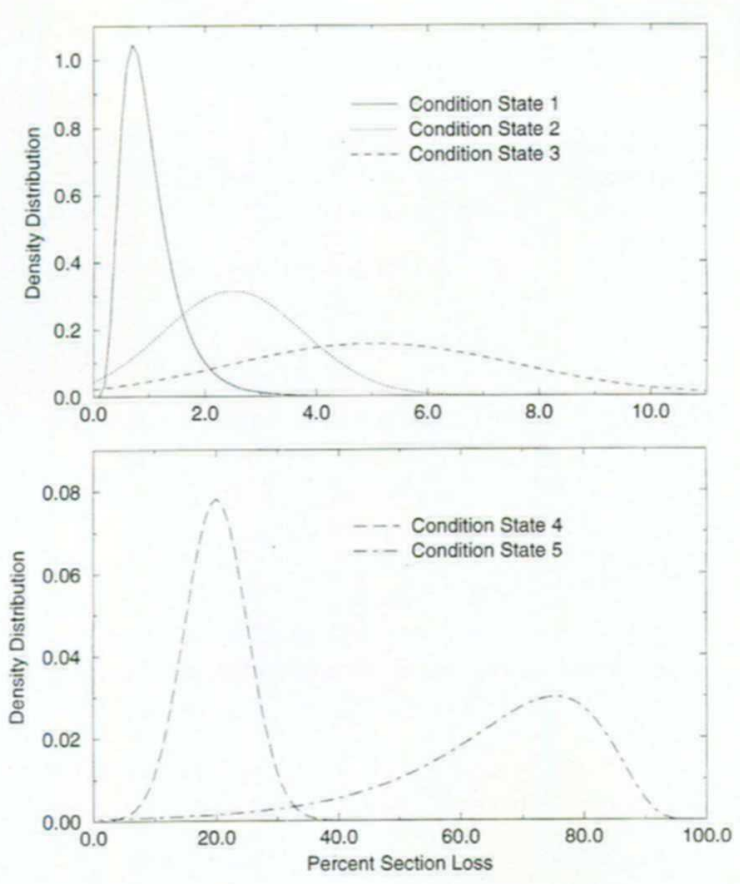

Fig. 6: Density distributions associated with Condition State (CS) ratings CS1-CS5 for Element 107: painted open steel girders; Inspection Category A

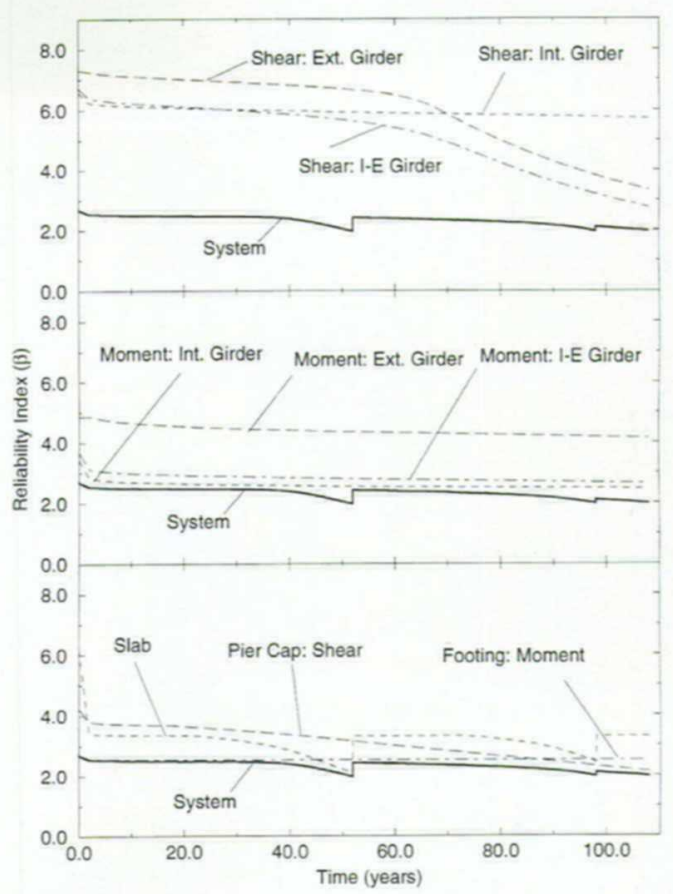

Fig. 7: Updated results of repair Option 1 on Bridge E-17-AH using simplified series-parallel model requiring the failure of three adjacent girders sessed. By performing the test at several points in time, the corrosion initiation time and its updated distribution can be determined as detailed in [2]. In this study, the updated values of the mean and standard deviation of the corrosion initiation time $T_{I}$ were $\mu_{T_{I}}=49.0$ years and $\sigma_{T_{l}}=15.0$ years, respectively. The original deterioration model predicted $\mu_{T_{t}}=19.6$ years and $\sigma_{T_{l}}=7.5$ years.

While the half-cell potential test indicates if active corrosion has begun, the corrosion rate determines the amount of section loss in the reinforcing steel which results in diminished moment capacity and reduced reliability. The three-electrode linear polarization test uses polarization resistance to determine the amount of electrical current flowing in actively corroding reinforcement. If a large flow of current is required to cause a specific change in electrical potential, the bar is corroding at a high rate. Conversely, if a small current flow is needed to cause the same change in potential, the bar is corroding more slowly. These current readings can be converted to corrosion rates as described in [11].

Using current readings taken at 38 locations on the structure and using only those readings where the half-cell potential was more negative than -0.35 volts, the updated parameters of the corrosion rate $r_{\text {corr }}$ for the embedded deck reinforcement are $\mu_{r_{\text {corr }}}=48.5 \mu \mathrm{m} / \mathrm{yr}$ and

$\sigma_{r_{\text {corr }}}=29.9 \mu \mathrm{m} / \mathrm{yr}$.

The values for $r_{\text {corr }}$ from the original deterioration model [4] were

$\mu_{r_{\text {corr }}}=50.7 \mu \mathrm{m} / \mathrm{yr}$ and

$\sigma_{r_{\text {corr }}}=5.8 \mu \mathrm{m} / \mathrm{yr}$.

The mean value of the corrosion rate is only slightly less than the one associated with the original model, but the standard deviation is about five times higher. Contrary to expectations, the inspection results reported here show greater uncertainty than assumed in the original model. With revised values for the corrosion initiation time $T_{I}$ and the rate of corrosion $r_{\text {corr }}$, the reliability of slab can be updated.

\section{Reliability Update of the Bridge}

Using the results of non-destructive inspections, the reliability of the girders, the deck, and ultimately the system are updated as described in [2]. Considering the same repair options listed earlier, Fig. 7 shows the results of Option 1: Replace the Deck. Fig. 7 can be compared to Fig. 3, which showed the time-dependent reliability of the bridge components and bridge system when the deck was replaced twice using the original deterioration models. Despite the updated inspection results, the figures are quite similar, except for the girder reliabilities with respect to shear. The girder reliabilities with respect to moment are close to the original model. The moment capacity is dependent on the plastic section modulus which is less sensitive to the small changes in the thickness loss. In Fig. 7, the slab is replaced at year 52 and year 98 , and at year 108 a slab repair is no longer sufficient to raise the system reliability above the target value of 2.0 .

With regard to the reliability of the system, the girder reliabilities do not dominate the system. The reduced uncertainty in the girder corrosion rate improves the reliability of the individual girders, but has little to no effect on the system. The slab, which is deteriorating more rapidly than the other bridge components, eventually dominates the reliability of the system. The effects of longer chloride initiation time $T_{I}$ and increased uncertainty in the corrosion rate $r_{\text {corr }}$ offset each other. As a result, the allowable (target) lifetime system reliability index of 2.0 is violated after 52 years of service (Fig. 7), which is very close to the 50 years of service in the earlier model (Fig. 3). Again, accounting for all relevant repair possibilities and using a discount rate of $2 \%$, Fig. 8 shows all feasible updated strategy options and their associated costs which can be compared to Fig. 4 using the original model. 


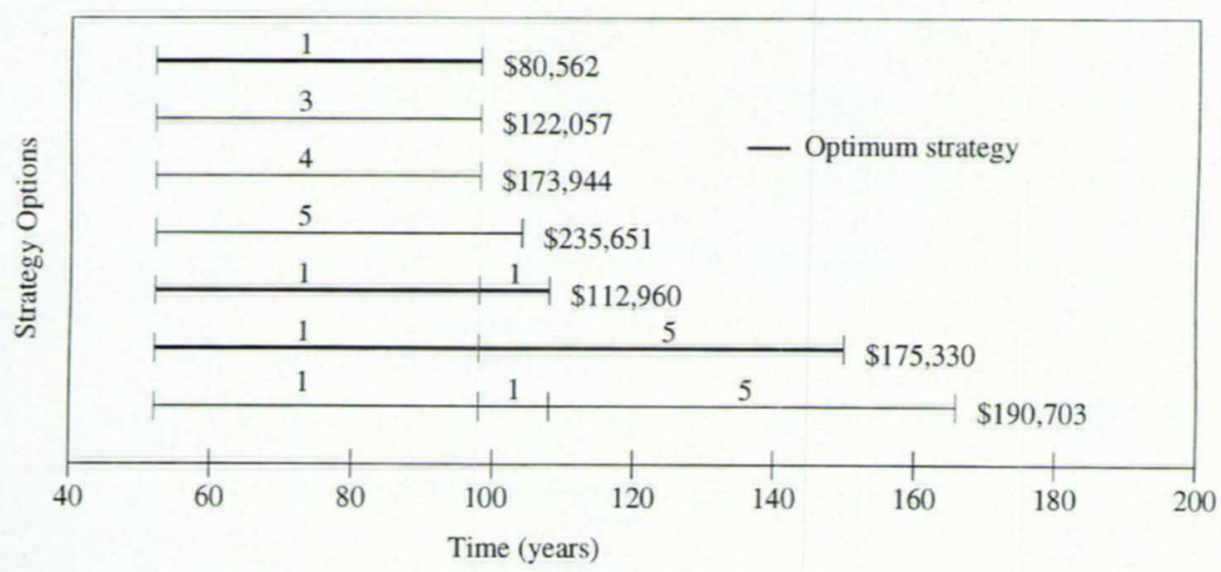

Fig. 8: Updated strategy options and associated costs for Bridge E-17-AH using simplified series-parallel model requiring the failure of three adjacent girders

As a result, the updated optimum repair strategy is as follows: for a life of 52 years, no action should be taken; for 52-98 years, replace the deck at year 52 (USD 80562); 98-108 years, replace the deck at year 52 and replace the deck again at year 98 (USD 112960); and after 108 years, replace the slab at year 52 and replace the bridge at year 108 (USD 175330). Updated inspection results would not always produce such minor changes in strategy. The lack of significant change in this update is due to the compensating differences in the deck results where the positive effect of an increase in the mean chloride initiation time was offset by a more uncertain corrosion rate. If the slab had been deteriorating more slowly and the girders more rapidly than the model suggested, then the updated lifetime bridge repair strategy would have been quite different.

\section{Concluding Remarks}

Using Colorado State Highway Bridge E-17-AH, this study illustrated how system reliability methods can be used to optimize the lifetime repair strategy while minimizing total repair cost and maintaining a prescribed level of system reliability. Because the initial strategy is based on assumptions that must be verified over the life of the structure, inspection results can be used to update the reliability of the structure and the repair strategy. With some reasonable assumptions, the biennial visual inspections can be used, but often the information provided is not sufficient, or the condition states are not well enough defined to update the reliability. The reliability update of a structure can be completed with much greater confidence if specific non-destructive evaluation inspection techniques are used to provide the relevant information. In this case, thickness tests, half-cell potential readings, and three-electrode linear polarization methods were used to update the reliability of the deck and the girders.

With the relevant non-destructive evaluation inspection techniques identified, the next step is to determine the optimum number and timing of these inspections over the life of the structure to minimize the expected lifecycle cost. As an example, [2] uses a given deck structure and optimizes the number of lifetime inspections and their intervals for the half-cell potential test.

As reliability theory has become better understood and accepted, the trend in research has moved toward more realistic and practical applications [12-15]. This study is just one example of a system reliability-based approach which guides the optimal allocation of economic resources for maintaining the lifetime safety of an existing bridge. This approach appears to be a useful method to minimize the expected repair costs of an existing structure while assuring a prescribed level of safety. The methods, however, are only as good as the input values for costs, modeling, and random variables. Continued research in this area is needed.

\section{References}

[1] FRANGOPOL, D. M. (Ed.). New Directions in Structural System Reliability. Univ. of Colorado, Boulder, CO, 1989.

[2] ESTES, A.C. A System Reliability Approach to the Lifetime Optimization of Inspection and Repair of Highway Bridges.
Ph.D. Thesis, Univ. of Colorado, Boulder, CO, 1997.

[3] NOWAK, A.S. Load Model for Bridge Design Code. Canadian Journal of Civil Engineering, Vol.21, No.1,1994, pp.36-49.

[4] THOFT-CHRISTENSEN, P; JENSEN, F. M.; MIDDLETON, C.R.; BLACKMORE, A. Assessment of the Reliability of Concrete Slab Bridges. Reliability and Optimization of Structural Systems. (D.M. Frangopol, R. B. Corotis, R.Rackwitz, Eds.), Pergamon (Elsevier), Oxford, 1997, pp. 321-328.

[5] ALBRECHT, P.; NAEEMI, A. H. Performance of Weathering Steel in Bridges. National Cooperative Highway Research Program, Report 272, 1984.

[6] CDOT (Colorado Dept of Transportation). 1994 Cost Data. Denver, CO, 1995.

[7] VERMA, D.; MOSES, F. Bridge Reliability - Evaluation vs. Design. Probabilistic Methods in Civil Engineering (P.D. Spanos, Ed.), ASCE, New York, 1986, pp. 233-236.

[8] CDOT. BMS/PONTIS Bridge Inspection Manual. Denver, CO, 1995.

[9] RENN, D. P. Segment-Based Inspection for Load Rating within Bridge Management Systems. M.S. Thesis, Univ. of Colorado, Boulder, CO, 1995.

[10] FHWA (Federal Highway Administration). Corrosion Detection in Reinforced Concrete Bridge Structures. User Manual, Demonstration Project No. 84, U.S. Dept of Transportation, Washington, DC, 1992.

[11] CLEAR, K.C. Measuring Rate of Corrosion of Steel in Field Concrete Structures. Transportation Research Record 1211. Transportation Research Board, National Research Council, Washington, DC, 1992.

[12] FRANGOPOL, D. M.; HEARN, G. Managing the Life-Cycle Safety of Deteriorating Bridges. Recent Advances in Bridge Engineering (Edited by J. R. Casas, F. W. Klaiber, and A.R. Mori). CIMNE, Barcelona, 1996 , pp. $38-55$.

[13] FRANGOPOL, D. M.; LIN, K-Y.; ESTES, A.C. Reliability of Reinforced Concrete Girders Under Corrosion Attack. Journal of Structural Engineering, ASCE, 123(3), 1997, pp. 286-297.

[14] FRANGOPOL, D. M.; LIN, K-Y; ESTES, A.C. Life-Cycle Cost Design of Deteriorating Structures. Journal of Structural Engineering. ASCE, 1997 (in print).

[15] ANG, A-H.S.; DE LEON, D. Target Reliability for Structural Design Based on Minimum Expected Life-Cycle Cost. In: Reliability and Optimization of Structural Systems (D. M. Frangopol, R. B. Corotis, R. Rackwitz, Eds.), Pergamon (Elsevier), Oxford, 1997, pp. 71-83. 